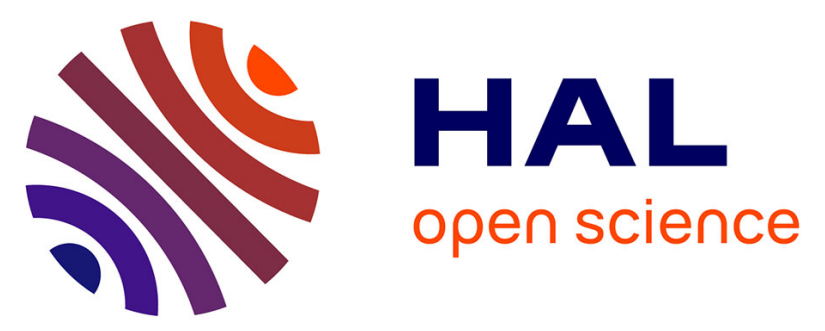

\title{
Can the maturity concept be used for separating autogenous shrinkage and thermal deformation of a cement paste at early age?
}

Ph Turcry, Ahmed Loukili, Laurent Barcelo, Jean Michel Casabonne

\section{- To cite this version:}

Ph Turcry, Ahmed Loukili, Laurent Barcelo, Jean Michel Casabonne. Can the maturity concept be used for separating autogenous shrinkage and thermal deformation of a cement paste at early age?. Cement and Concrete Research, 2002, 32 (9), pp.1443-1450. 10.1016/S0008-8846(02)00800-1 . hal-01005844

\section{HAL Id: hal-01005844 \\ https://hal.science/hal-01005844}

Submitted on 5 Dec 2018

HAL is a multi-disciplinary open access archive for the deposit and dissemination of scientific research documents, whether they are published or not. The documents may come from teaching and research institutions in France or abroad, or from public or private research centers.
L'archive ouverte pluridisciplinaire HAL, est destinée au dépôt et à la diffusion de documents scientifiques de niveau recherche, publiés ou non, émanant des établissements d'enseignement et de recherche français ou étrangers, des laboratoires publics ou privés. 


\title{
Can the maturity concept be used to separate the autogenous shrinkage and thermal deformation of a cement paste at early age?
}

\author{
Philippe Turcry ${ }^{\mathrm{a}}$, Ahmed Loukili ${ }^{\mathrm{a}, *}$, Laurent Barcelo ${ }^{\mathrm{b}}$, Jean Michel Casabonne ${ }^{\mathrm{b}}$ \\ ${ }^{a}$ Laboratoire Génie Civil de Nantes St-Nazaire, Ecole Centrale de Nantes, BP 92101, 44321 Nantes Cedex, France \\ ${ }^{\mathrm{b}}$ LAFARGE, Laboratoire Central de Recherche, 95 rue du Montmurier, 38290 St-Quentin Fallavier, France
}

The influence of temperature on the autogenous shrinkage of cement paste has been studied using the maturity approach based on Arrhenius' law. Application of this law requires knowledge of the apparent activation energy, $E_{\mathrm{a}}$, of cement. In this work, $E_{\mathrm{a}}$ has been determined by the "setting time method." The external volume change of cement paste was measured by hydrostatic weighing. In order to separate the thermal and autogenous deformations, the thermal dilation coefficient (TDC) was determined at both 20 and $30{ }^{\circ} \mathrm{C}$. Investigations have shown that maturity can be used to predict autogenous shrinkage under isothermal and realistic conditions as long as temperatures remain between 10 and $40{ }^{\circ} \mathrm{C}$. Outside of this temperature range, the calculated autogenous deformation and measured isothermal shrinkage are quite different and, as a result, autogenous shrinkage appears to be dependent on more than hydration advancement alone.

Keywords: Autogenous shrinkage; Temperature; Cement paste; Early age; Maturity concept

\section{Introduction}

At early age, thermal deformations and autogenous shrinkage occur simultaneously and may, if restrained, lead to the cracking of cementitious materials. These thermal deformations, $\varepsilon_{\text {th }}$, result from the temperature rise caused by hydration reactions and are proportional to the thermal dilation coefficient (TDC) of the cement paste: $\varepsilon_{\mathrm{TH}}=$ $\mathrm{TDC} \times \Delta T$. Autogenous shrinkage, on the other hand, is a consequence of chemical shrinkage: hydration products are denser than the unhydrated compounds. In the plastic state, this contraction is converted into settlement. Once the solid skeleton has been formed and in the absence of an external source of water, hydration reactions continue through the consumption of capillary water. This phenomenon is called "self-desiccation." According to the Kelvin equation, this self-desiccation gradually increases the tensile stress in pore water, which then leads to a global compressive stress on the

\footnotetext{
* Corresponding author. Tel.: +33-2-40-37-16-67; fax: +33-2-40-3725-35.

E-mail address: ahmed.loukili@ec-nantes.fr (A. Loukili).
}

solid skeleton. A deformation, called autogenous shrinkage, $\varepsilon_{\text {as }}$, thereby occurs.

For the calculation of stresses at early age, autogenous shrinkage is assumed to be dependent solely on the degree of hydration, $\alpha$, with $\varepsilon_{\text {as }}=\varepsilon_{\text {as }}(\alpha)$, and total deformation is taken as equal to the sum of thermal and autogenous deformations, i.e., $\varepsilon_{\text {total }}=\varepsilon_{\text {as }}+\varepsilon_{\text {th }}$ [1]. However, recent studies $[2,3]$ have shown that the autogenous shrinkage amplitude of concrete is influenced by the temperature history. It seems that for a given degree of hydration, concretes with different temperature histories do not develop the same autogenous shrinkage. These results question the applicability of the maturity concept.

This paper focuses on the influence of temperature on the autogenous shrinkage of cement paste by use of the maturity concept [4]. The rate of chemical reactions is affected by temperature, since cement hydration is thermally activated. Moreover, the microstructure itself will undergo change when formed at different temperatures. The maturity concept serves to predict the effect of temperature on certain material properties with respect to the degree of hydration (e.g., compressive strength). This concept is based on Arrhenius' law, which requires determining the thermal 
sensitivity of hydration reactions, called the apparent activation energy, $E_{\mathrm{a}}$.

This study deals first with the determination of apparent activation energy by using the setting time method $[5,6]$. Deformations of the cement paste at early age were measured for different thermal conditions, both isothermal and "realistic." The method chosen to assess volume change was the measurement of buoyancy variations for a sample in a flexible latex mold through hydrostatic weighing, as presented in detail elsewhere in the literature [3]. With this method, we also measured the TDC, which has allowed calculating thermal deformations in the realistic cases. Lastly, using the maturity approach, we have attempted to separate thermal deformation from autogenous shrinkage.

\section{Materials and experimental methods}

\subsection{Materials}

An ordinary type I Portland cement (CPA CEM I 52.5 $\mathrm{CP} 2$ ), containing $60 \% \mathrm{C}_{3} \mathrm{~S}, 12 \% \mathrm{C}_{2} \mathrm{~S}, 9 \% \mathrm{C}_{3} \mathrm{~A}$, and $8 \%$ $\mathrm{C}_{4} \mathrm{AF}$, was used. The Blaine specific surface was $332 \mathrm{~m}^{2} / \mathrm{kg}$. The water-to-cement (W/C) ratio was 0.25 . Cement and water were mixed for $3 \mathrm{~min}$ in order to ensure a homogeneous mix.

\subsection{Experimental methods}

\subsubsection{Determination of $E_{a}$ by means of the setting times method}

The maturity concept determines the time required at a reference temperature for the cement paste to achieve the same level of development as that under the influence of the actual time-temperature history. This time is called the "equivalent age" and can be calculated by a function based on Arrhenius' law (Eq. (1)):

$\tau_{\text {equ }}=\int_{0}^{t} \exp \left(\frac{E_{\mathrm{a}}}{R}\left(\frac{1}{273+\theta_{\text {ref }}}-\frac{1}{273+\theta(t)}\right)\right) \mathrm{d} t$

where $\tau_{\text {equ }}$ is the equivalent age at the reference temperature, $\theta_{\text {ref }}(\mathrm{h}), t$ is the paste age $(\mathrm{h}), \theta(t)$ is the paste temperature at time $t\left({ }^{\circ} \mathrm{C}\right), \theta_{\text {ref }}$ is the reference temperature $\left({ }^{\circ} \mathrm{C}\right), E_{\mathrm{a}}$ is the apparent activation energy $(\mathrm{J} / \mathrm{mol})$, and $R$ is the universal gas constant $(\mathrm{J} / \mathrm{mol} / \mathrm{K})$.

The following proposed relation has been demonstrated theoretically [5]:

$\ln \left(\frac{\Delta \alpha}{\Delta t}\right)=-\frac{E_{\mathrm{a}}}{R}\left(\frac{1}{T_{0}}\right)+$ constant

where $T_{0}$ is the temperature of the paste $(\mathrm{K})$ under isothermal conditions and $\Delta t$ is the time required to increase the degree of hydration by an increment $\Delta \alpha$ at $T_{0}$. By plotting the time $\Delta t$ for different temperatures $T_{0}$, we can deduce $E_{\mathrm{a}}$. Nevertheless, a way must be found to characterize the degree of hydration $\alpha$. The setting time method presumes that both the initial set time, $t_{\text {is }}$, and final set time, $t_{\mathrm{fs}}$, are reached for definite levels of hydration (at a given $\mathrm{W} /$ $\mathrm{C}$ ratio). This method therefore consists of measuring these specific times $\left(t_{\mathrm{is}}\right.$ and $\left.t_{\mathrm{fs}}\right)$ for several isothermal conditions and, in the subsequent step, calculating an activation energy for each period, initial setting and setting $\left(t_{\mathrm{fs}}-t_{\mathrm{is}}\right)$.

Initial set time and setting time of cement pastes were measured using the Vicat needle apparatus, which operates in accordance with European Standard EN 196-3. The samples were placed in a water bath at various temperatures $\left(10,20,30\right.$, and $\left.40^{\circ} \mathrm{C}\right)$. The temperature inside the samples was measured through embedded thermocouples.

\subsubsection{External volume change}

Measurements of the external volume change of cement paste were conducted through hydrostatic weighing. Immediately after casting, a prophylactic without lubricant was filled with cement paste in order to form a spherical sample. The latex mold was closed using a thin stainless steel wire. The excess latex was then cut and the sample container was cleaned and weighed. The sample was hung under a balance and immediately immersed in the water bath at the chosen temperature. The sample mass was approximately $90 \mathrm{~g}$. The bath temperature was controlled by a "cryo-thermostat" (Fig. 1) with an accuracy of $0.1{ }^{\circ} \mathrm{C}$. The external volume change results from a change in the buoyancy force and serves to alter the weight reading on the balance. Both the bath temperature and measured mass were continuously logged on the computer at 5-min intervals for a period exceeding $24 \mathrm{~h}$.

In realistic tests, the bath temperature is imposed by a cement paste sample placed in a quasi-adiabatic enclosure after casting. The temperature is measured by a thermocouple introduced into the cement paste. The weighed sample therefore undergoes the same temperature history. A detailed description of this system is provided in Ref. [3]. In order to obtain different temperature histories (Fig. 2), the mass of the sample placed in the enclosure is changed.

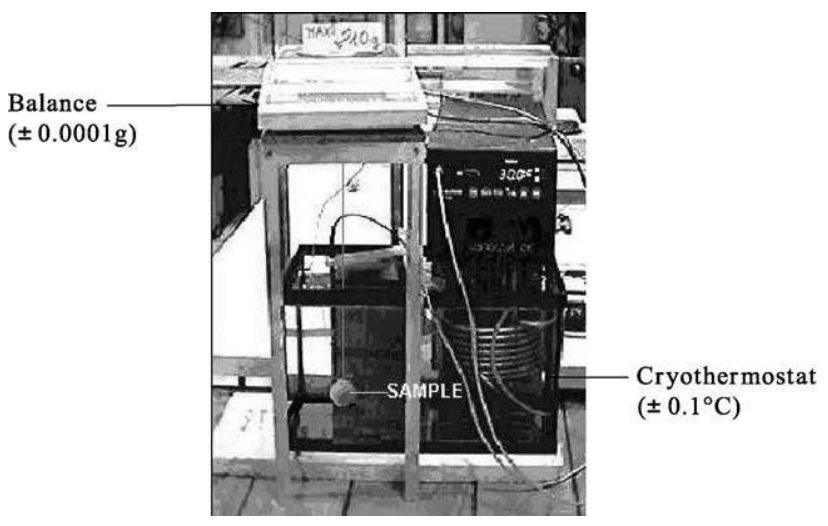

Fig. 1. Experimental system. 


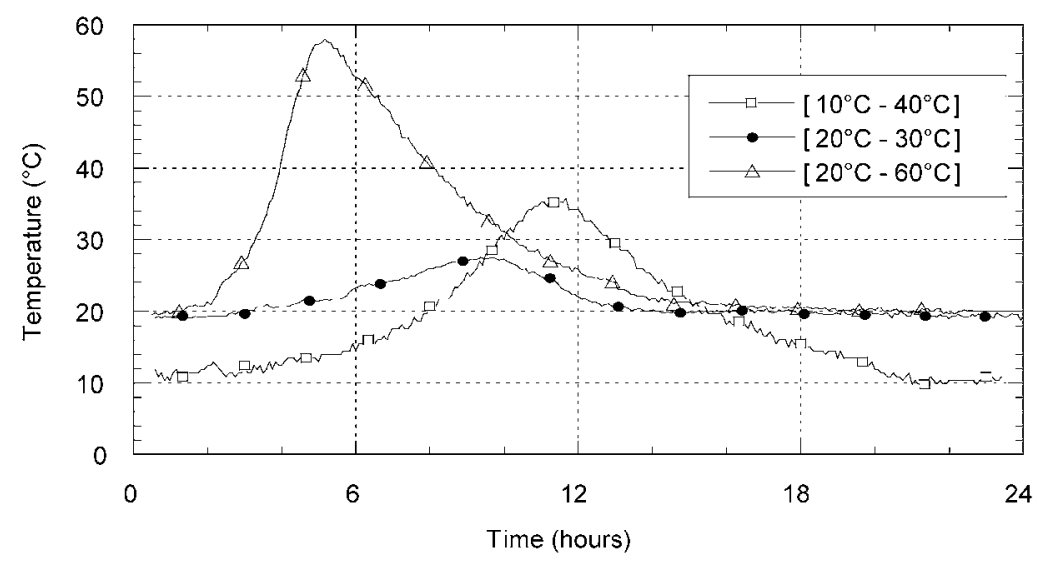

Fig. 2. Different realistic temperature histories.

\subsection{Calculation of the deformations}

The external shrinkage, expressed in cubic millimeters per gram cement, was obtained from Eq. (3) as a result of the calculation already discussed in detail [3]:

$\frac{\Delta V}{M_{\mathrm{c}}}=\left[\left(\frac{\rho_{\mathrm{iw}}}{\rho_{\mathrm{w}}(T)}-1\right)-\frac{M_{\mathrm{r}}}{V_{\mathrm{i}} \rho_{\mathrm{w}}(T)}\right] \frac{V_{i}}{M_{\mathrm{c}}}$

where $T$ is the bath temperature $\left({ }^{\circ} \mathrm{C}\right), \rho_{\text {iw }}$ is the initial density of water $\left(\mathrm{g} / \mathrm{cm}^{3}\right), \rho_{\mathrm{w}}(T)$ is the density of water as a function of temperature $\left(\mathrm{g} / \mathrm{cm}^{3}\right), V_{\mathrm{i}}$ is the initial sample volume $\left(\mathrm{cm}^{3}\right), \Delta V$ is the volume change $\left(\mathrm{cm}^{3}\right), M_{\mathrm{r}}$ is the mass reading on the balance $(\mathrm{g})$, and $M_{\mathrm{c}}$ the cement mass in the sample $(\mathrm{g})$.

\section{Results and discussion}

\subsection{Determination of $E_{a}$ by the setting times method}

The results related to the initial set and setting times determined by the Vicat needle device have been listed in Table 1. Both the initial set and setting time increase with decreasing temperature. This finding has been previously reported.

Figs. 3 and 4 were drawn by assuming isothermal conditions until the initial set; a linear curve was fitted to the data points. According to Eq. (2), the computed apparent activa-

Table 1

Initial set and setting time at different temperatures

\begin{tabular}{llc}
\hline $\begin{array}{l}\text { Average } \\
\text { temperature }\left({ }^{\circ} \mathrm{C}\right)\end{array}$ & $\begin{array}{l}\text { Initial set time, } \\
t_{\text {is }}(\mathrm{min})\end{array}$ & $\begin{array}{l}\text { Setting time, } \\
t_{\mathrm{fs}}-t_{\text {is }}(\mathrm{min})\end{array}$ \\
\hline 12 & 150 & 138 \\
20 & 110 & 90 \\
34 & 70 & 50 \\
37 & 60 & 30 \\
\hline
\end{tabular}

tion energies were $29 \mathrm{~kJ} / \mathrm{mol}$ for the time periods until the initial set and $39 \mathrm{~kJ} / \mathrm{mol}$ between the initial and final sets.

This procedure yields two activation energies, which is not unrealistic since $E_{\mathrm{a}}$ reflects more of a mathematical than a chemical tool, thereby making it possible to estimate the global thermal sensitivity of all reactions taking place in the hydrating cement paste.

\subsection{Isothermal tests at $10,20,30$, and $40^{\circ} \mathrm{C}$}

Exposed to each temperature, the external shrinkage was determined as the mean value of three measurements and

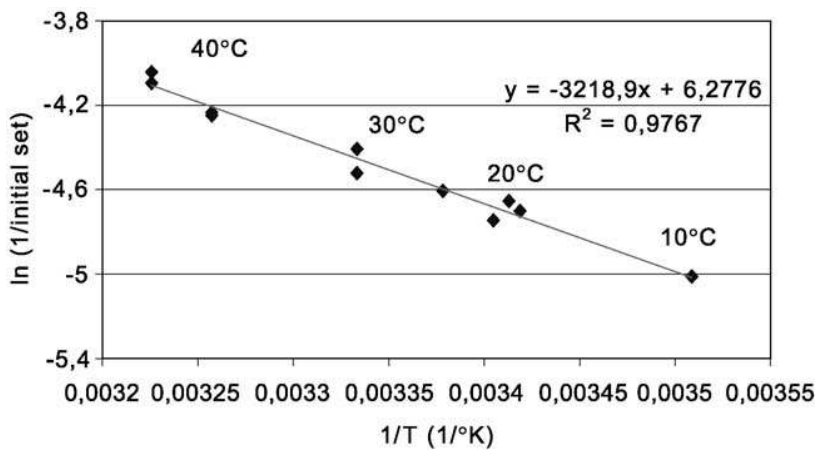

Fig. 3. Arrhenius plot for initial set times.

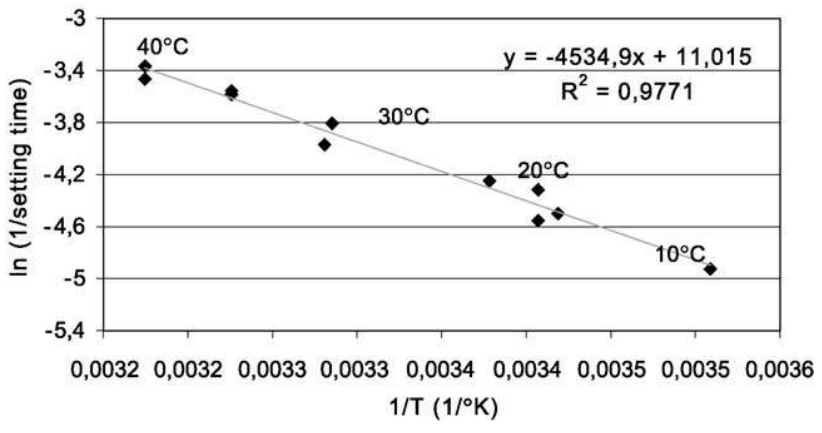

Fig. 4. Arrhenius plot for setting time. 


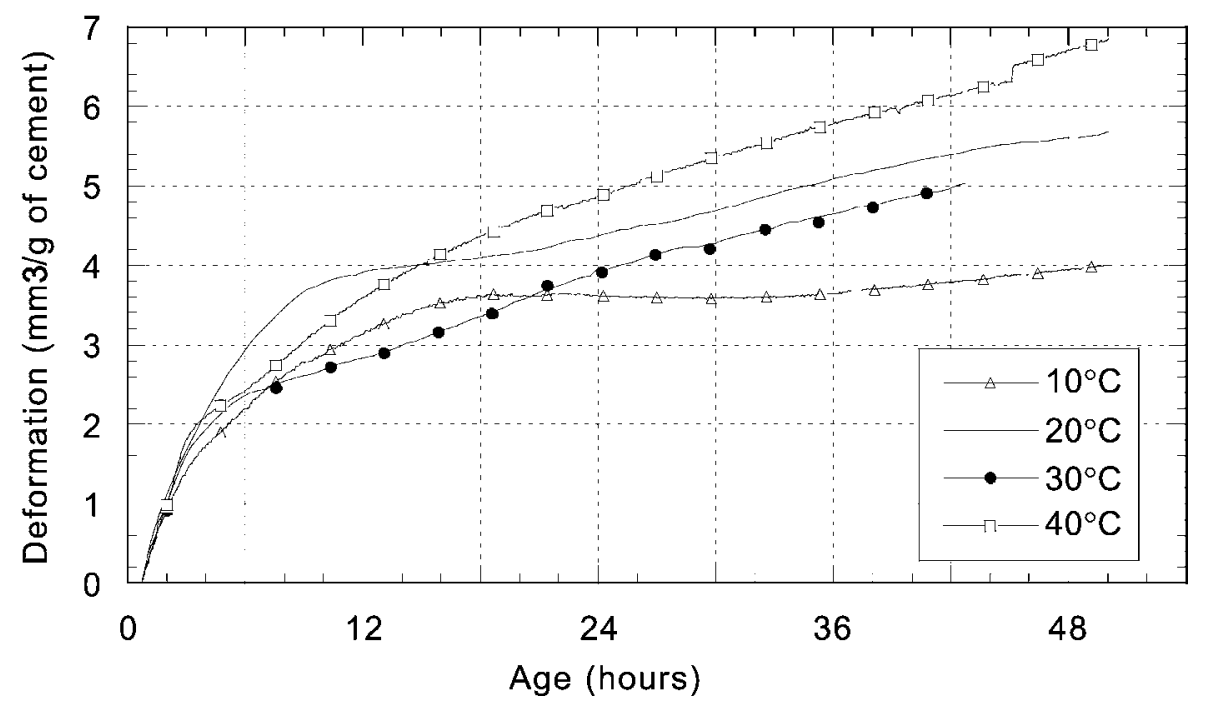

Fig. 5. Comparison of deformation for different temperatures versus paste age.

expressed in cubic millimeters per gram of cement, with a variation of less than $8 \%$.

The external shrinkage at different temperatures versus real time has been plotted in Fig. 5. It can be observed that temperature has an unsystematic effect on the autogenous deformation of cement paste. This result, which has also been reported by Bjøntegaard [2], is not surprising since the comparison was conducted in an inconsistent manner by virtue of not incorporating the temperature effect on the rate of cement hydration, which is responsible for autogenous deformations. Comparing autogenous shrinkage curves versus real age is similar to comparing different materials; in this case, we need to apply the maturity concept.

Fig. 6 shows deformation curves versus equivalent age, which has been calculated for each temperature using Eq. (1). $E_{\mathrm{a}}$ is taken as equal to $29 \mathrm{~kJ} / \mathrm{mol}$ before the initial set and $39 \mathrm{~kJ} / \mathrm{mol}$ thereafter. The reference temperature is $20{ }^{\circ} \mathrm{C}$ (as results obtained at $20{ }^{\circ} \mathrm{C}$ do not change with time transformation). It is important to note that deformations must be initialized at the same equivalent age, i.e., for the same theoretical degree of hydration. The selected equivalent time origin was $3.25 \mathrm{~h}$, in correspondence with the final set time (Fig. 6). It can be seen that the four curves follow similar trends with just little scatter, which is caused by measurement accuracy levels. The maturity concept therefore leads to predicting with reasonable accuracy the autogenous shrinkage of cement paste under isothermal conditions over the $10-40{ }^{\circ} \mathrm{C}$ range.

\subsection{External volume change in realistic cases}

By considering the behavior of material to be isotropic, linear deformation represents one-third of the volumetric

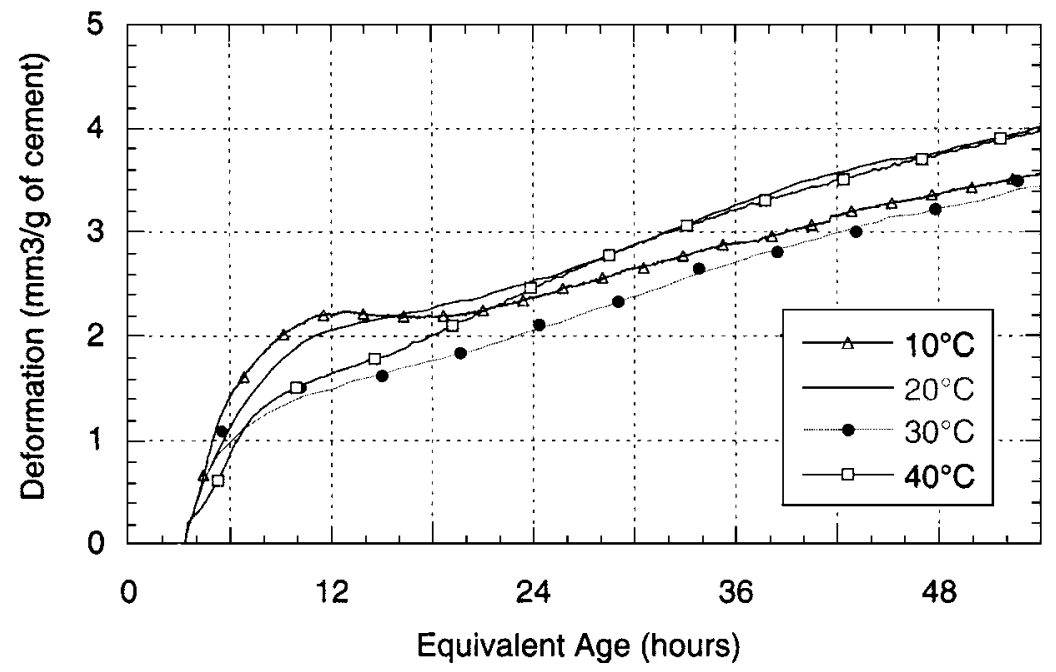

Fig. 6. Autogenous deformation for different temperatures versus maturity, starting after $3.25 \mathrm{~h}$. 


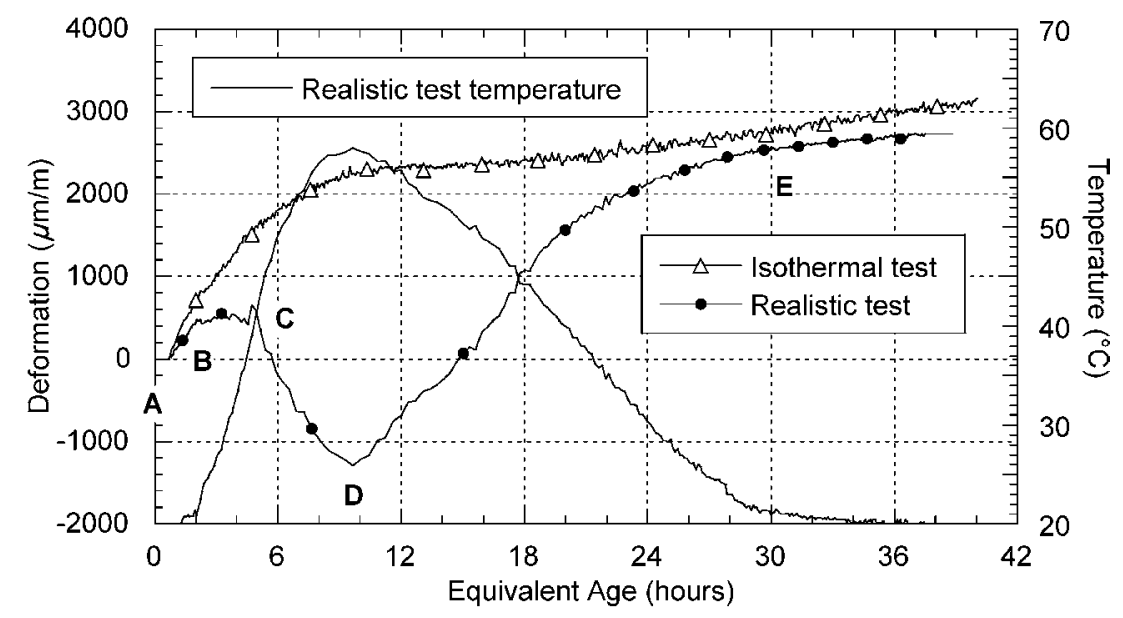

Fig. 7. Comparison of the isothermal test at $20{ }^{\circ} \mathrm{C}$ and the $20-60{ }^{\circ} \mathrm{C}$ realistic test.

deformation calculated in Eq. (3). In this part, deformations are expressed in micrometers per meter.

\subsubsection{Deformation kinetics}

Three realistic temperature tests with initial temperatures of 10 and $20^{\circ} \mathrm{C}$ were performed. A typical curve of a realistic temperature history $\left(20-60{ }^{\circ} \mathrm{C}\right)$ is illustrated in Fig. 7 .

The realistic deformation curve can be divided into four phases: $\mathrm{AB}, \mathrm{BC}, \mathrm{CD}$, and $\mathrm{DE}$. In the first phase, it is observed that the isothermal and realistic deformations display the same shape since the temperature is constant in both tests. When temperature increases in the realistic test (B), the curves diverge; during BC, no "realistic" deformation is recorded. It seems that thermal deformations compensate for autogenous shrinkage. In the case of the "realistic" test, thermal expansion occurs until the temperature peak (CD), while the rate of autogenous shrinkage at $20{ }^{\circ} \mathrm{C}$ is decreasing. During the cooling period (DE), a large deformation caused by both thermal contraction and autogenous shrinkage can be observed. Moreover, when the temperature returned to $20{ }^{\circ} \mathrm{C}$, the magnitude of the "realistic" deformation corresponds to the autogenous shrinkage recorded under isothermal conditions. It can thereby be

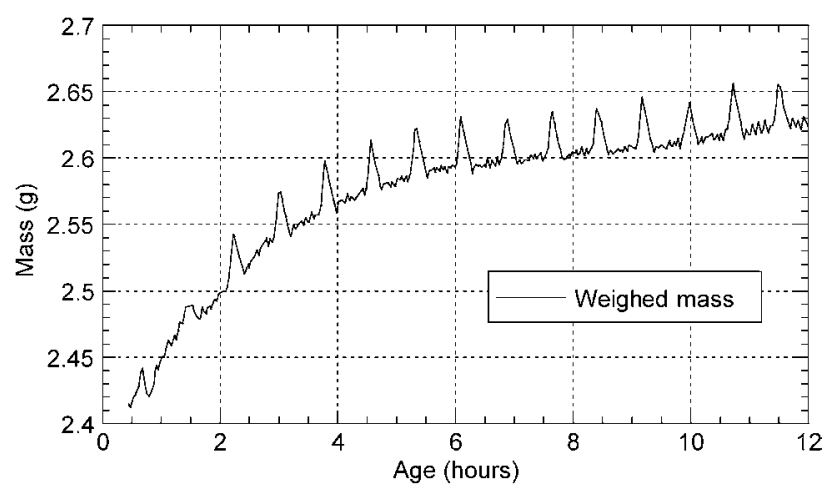

Fig. 8. Evolution in mass readings during the TDC measurement. stated that the total measured deformation under realistic conditions is equal to the sum of the measured deformation in the isothermal test and a thermal component related to temperature history. In order to separate thermal and autogenous deformations, we have determined the evolution of the TDC with respect to time.

\subsection{TDC measurements}

The TDC was measured with the method of spontaneous heating by using hydrostatic weighing [3]. Tests were carried out under two isothermal conditions: 20 and 30 ${ }^{\circ} \mathrm{C}$. Every hour, the bath temperature was increased by $4{ }^{\circ} \mathrm{C}$ within a period of about $7 \mathrm{~min}$ and then immediately decreased to the isothermal temperature. Fig. 8 presents the evolution in weight given by the balance without any water density correction. Note that the $4{ }^{\circ} \mathrm{C}$ peak effect is different at very early age and after $2 \mathrm{~h}$, which reveals an evolution in the TDC.

By using this method for the TDC calculation, it was assumed that the temperature rise was sufficiently fast for the deformation measured during heating to be consid-

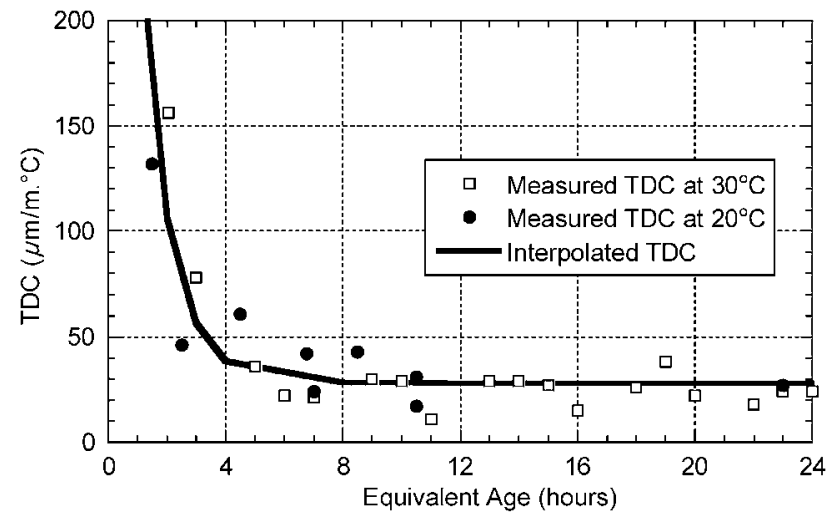

Fig. 9. TDC evolution. 


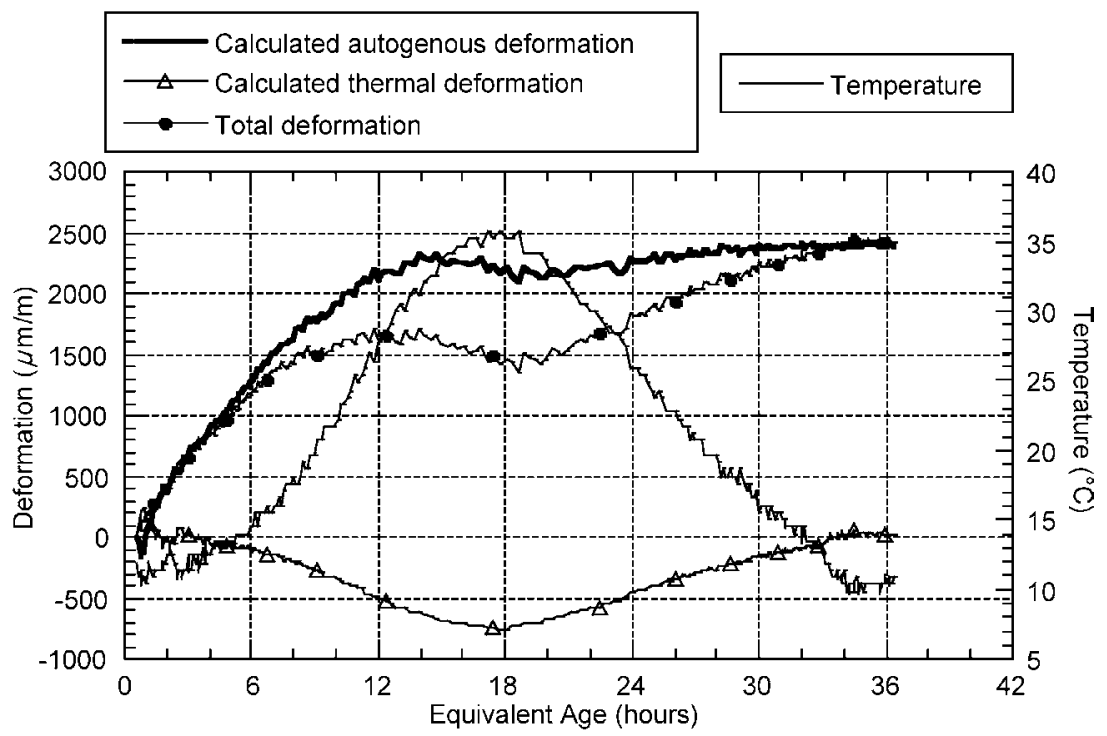

Fig. 10. Separation of thermal and autogenous deformations for the $10-40{ }^{\circ} \mathrm{C}$ temperature history.

ered only from a thermal origin. In spite of the dispersion of experimental points (Fig. 9), TDC seems to depend solely on equivalent age (with $\theta_{\text {ref }}=20{ }^{\circ} \mathrm{C}$ ). A TDC curve may be interpolated from our results in accordance with Eq. (4) below:

$\operatorname{TDC}\left(t_{\text {equ }}\right)=137 * \exp \left(1.44-t_{\text {equ }}\right)+28$.

It is observed in Fig. 9 that the TDC decreases sharply during the first few hours after casting and then remains constant from $8 \mathrm{~h}$ onwards. Its value is high $\left(28 \mu \mathrm{m} / \mathrm{m}{ }^{\circ} \mathrm{C}\right)$, yet in agreement with other cement paste TDC reported by other researchers [7]. Miao et al. [8] reported a TDC of about $24 \mu \mathrm{m} / \mathrm{m}{ }^{\circ} \mathrm{C}$ at $7 \mathrm{~h}$ after casting for a concrete with a $\mathrm{W} / \mathrm{C}$ ratio of 0.28 . It should be noted that the TDC value is very sensitive to the experimental measurement procedure used.

\subsection{Separation of thermal and autogenous deformations}

Interpolated TDC allows determining the thermal deformation for any temperature history. We can also deduce autogenous deformation from total deformation by assuming that total deformation is the sum of the two other components. Moreover, deformation separation has to be performed by application of the maturity concept. Fig. 10 presents an example of separation in the case of the $10-40{ }^{\circ} \mathrm{C}$ realistic test.

\subsection{Maturity concept approach results and discussion}

Figs. 11 and 12 compare isothermal shrinkage at 10 and $20{ }^{\circ} \mathrm{C}$, respectively, and calculate autogenous deformation. It can be observed that although the determined TDC is rather inaccurate, both the calculated and measured defor-

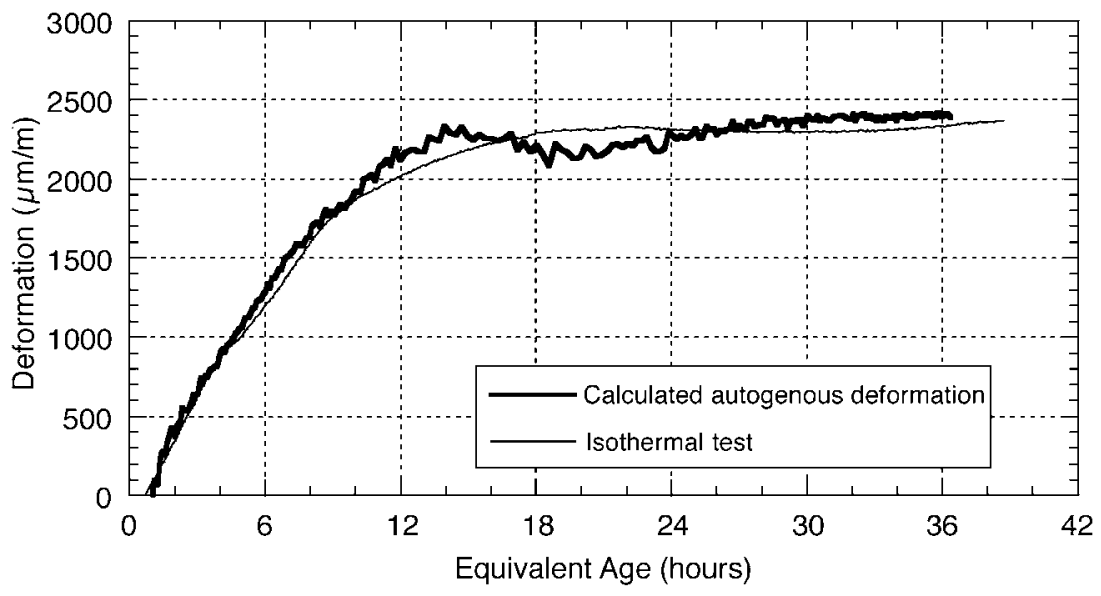

Fig. 11. Comparison of the measured autogenous shrinkage at $10{ }^{\circ} \mathrm{C}$ and the calculated autogenous deformation for the $10-40{ }^{\circ} \mathrm{C}$ test. 


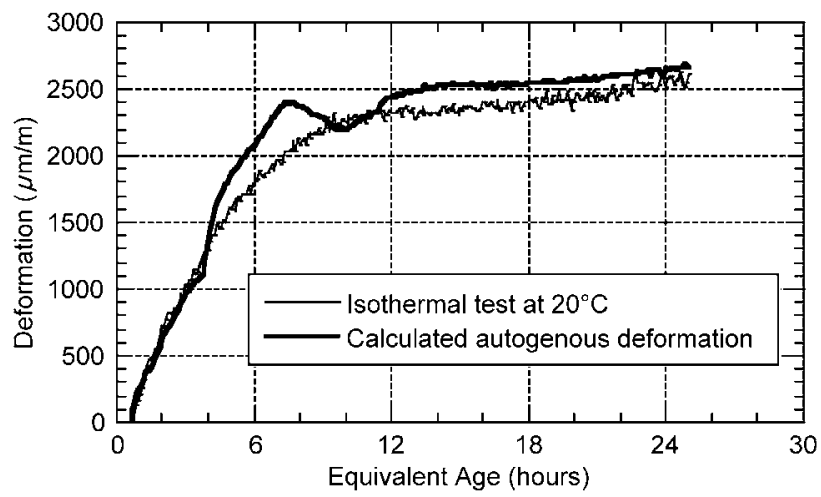

Fig. 12. Comparison of the measured autogenous shrinkage at $20{ }^{\circ} \mathrm{C}$ and the calculated autogenous deformation for the $20-30{ }^{\circ} \mathrm{C}$ test.

mations are nearly identical. The maturity approach provides a good estimate of the autogenous shrinkage of cement paste.

However, the method used to separate thermal and autogenous deformations yields a different result for the 20-60 ${ }^{\circ} \mathrm{C}$ test (Fig. 13). In this instance, the final amplitude of the calculated autogenous deformation is about $700 \mu \mathrm{m} / \mathrm{m}$ higher than that measured in the isothermal test at $20{ }^{\circ} \mathrm{C}$. Moreover, the calculated deformation displays a significant dilation peak. In other words, the usually expected kinetics of autogenous shrinkage is not present herein.

In Fig. 13, it is observed that the final amplitude of the calculated autogenous deformation is nearly equal to the amplitude of isothermal shrinkage plus the final amplitude of thermal deformation. In fact, thermal deformation is not reversible because of TDC evolution: during the heating period, TDC is higher than the cooling phase and, consequently, temperature variations induce dilation. In the $10-$ $40{ }^{\circ} \mathrm{C}$ test (Fig. 11), no dilation can be detected; paste heating and cooling must therefore occur at a time when TDC is constant.

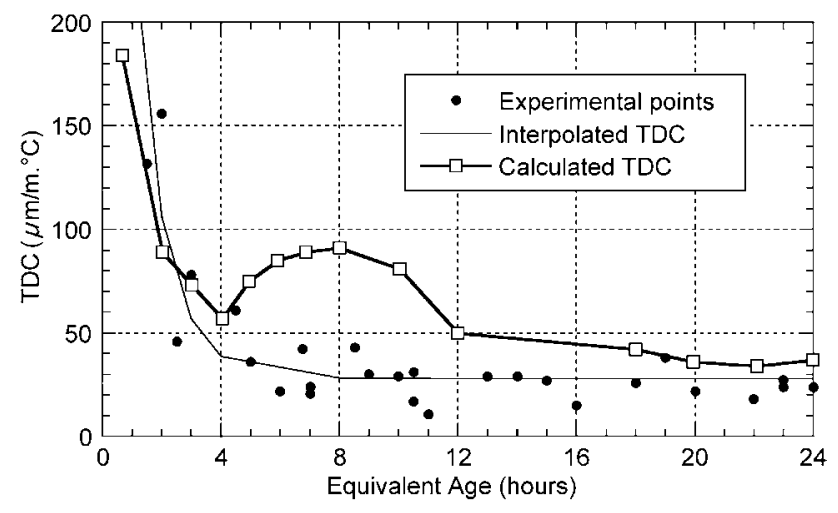

Fig. 14. Comparison of Laplante method TDC and experimental TDC.

At this juncture, two assumptions can be made. Firstly, the maturity concept cannot predict autogenous deformation evolution and amplitude when the thermal history lies beyond a temperature field between 10 and $40{ }^{\circ} \mathrm{C}$. The maturity concept is a mathematical tool that may be too simplistic for describing microstructural changes. For example, the hydration product form, and therefore chemical shrinkage, may be different at $20{ }^{\circ} \mathrm{C}$ than at $60{ }^{\circ} \mathrm{C}$.

The validity of the determined TDC can also be questioned. Indeed, this TDC does not allow entirely separating thermal and autogenous deformations in the $20-60{ }^{\circ} \mathrm{C}$ test. For example, dilation observed in the calculated autogenous deformation may be from a thermal origin. Afterwards, we determined a theoretical TDC that allows obtaining the same autogenous shrinkage by means of calculation as by isothermal measurement. This method has been developed by Laplante [1]. Thermal deformation is presumed to be obtained by subtracting the measured isothermal deformation from the measured total deformation. TDC is equal to the ratio of this deformation to the temperature difference between isothermal and realistic tests.

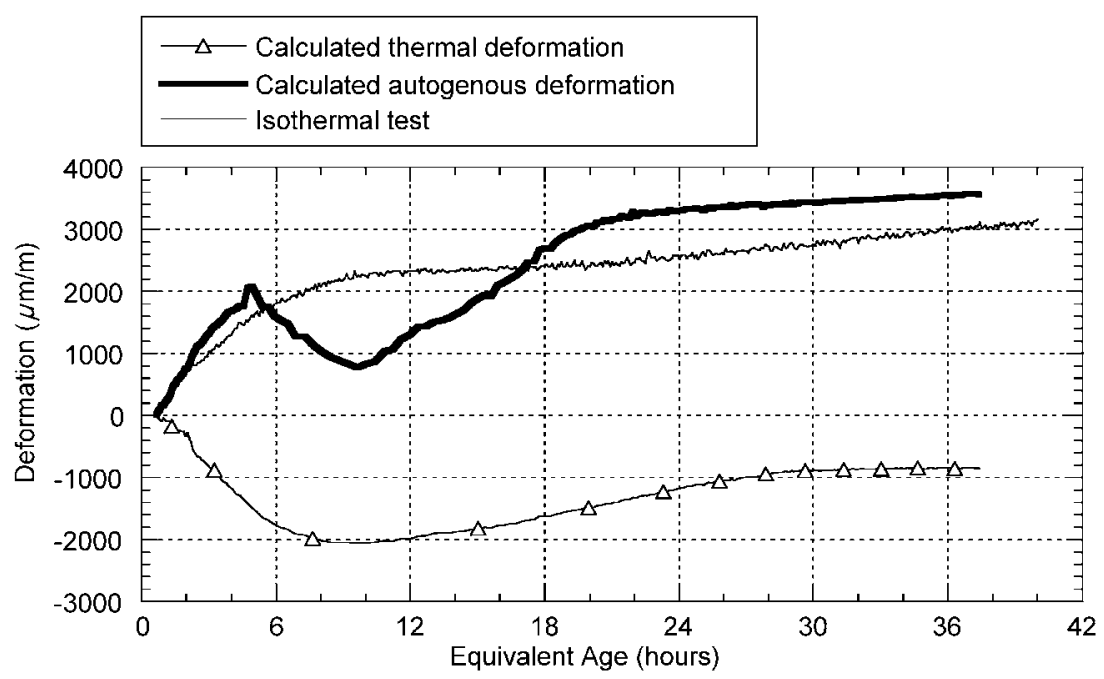

Fig. 13. Comparison of the measured autogenous shrinkage at $20{ }^{\circ} \mathrm{C}$ and the calculated autogenous deformation for the $20-60{ }^{\circ} \mathrm{C}$ test. 
Fig. 14 compares experimental TDC from isothermal tests and TDC calculated using the Laplante method. It is shown that the calculated coefficient does not present a typical evolution. TDC may be dependent on thermal history when the temperature of realistic history exceeds a certain limit. This result reveals the need for further work in TDC measurement, for example, in the realistic case.

\section{Conclusions and subsequent work}

Based on the assumption that the maturity concept is applicable throughout the hydration process, the following conclusions can be drawn:

- Between 10 and $40{ }^{\circ} \mathrm{C}$, the maturity concept allows predicting the isothermal autogenous shrinkage of cement paste measured using the volumetric method: autogenous shrinkage thus seems to be solely dependent on the degree of hydration.

- In realistic tests, total deformation is shown in an initial analysis to be the sum of autogenous and thermal components. Separation of thermal and autogenous deformations is therefore made possible by use of a valuable TDC.

- The TDC is linked to the degree of hydration only between 20 and $30{ }^{\circ} \mathrm{C}$.

- The maturity concept allows estimating the autogenous deformation amplitude for thermal conditions between 10 and $40{ }^{\circ} \mathrm{C}$ by measuring the isothermal shrinkage.

- For the $20-60{ }^{\circ} \mathrm{C}$ realistic test, both the calculated autogenous deformation and isothermal measured shrinkage differ. Autogenous deformation therefore seems to be affec- ted by thermal history above $40{ }^{\circ} \mathrm{C}$. Nonetheless, a process must be developed in the future to accurately measure TDC under different thermal conditions: both isothermal and realistic. These results also need to be verified by means of linear tests.

\section{References}

[1] P. Laplante, Propriétés Mécaniques des bétons durcissants : Analyse Comparée des Bétons Classiques et à Très Hautes Performances, $\mathrm{PhD}$ thesis, Ecole Nationale des Ponts et Chaussées, Paris, 1993 (in French).

[2] Ø. Bjøntegaard, Thermal dilation and autogenous deformation as driving forces to self-induced stresses in high performance concrete, $\mathrm{PhD}$ thesis, The Norwegian University of Science and Technology, N-7491 Trondheim, 1999.

[3] A. Loukili, D. Chopin, A. Khelidj, J.Y. Le Touzo, A new approach to determine autogenous shrinkage of mortar at early age considering temperature history, Cem. Concr. Res. 30 (6) (2000) 915-922.

[4] P. Laplante, S. Roussel, S. Lecrux, Technique maturométrique: la loi d'Arrhénius au service des chantiers, Proceedings of the International RILEM Conference, RILEM Publications, Arles, France, 1998, pp. 323-342 (in French).

[5] L. D'Aloia, Détermination de l'énergie d'activation apparente du béton dans le cadre de l'application de la méthode du temps équivalent à la prévision au jeune âge: approches expérimentales mécaniques et calorimétrique, simulations numériques, $\mathrm{PhD}$ thesis, Institut National des Sciences Appliquées de Lyon, 1998 (in French).

[6] R.C.A. Pinto, K.C. Hover, Application of maturity approach to setting times, ACI Mater. J. 96 (6) (1999) 686-691.

[7] N. Bouzoubaa, Thermal dilation coefficient of concrete, University of Sherbrooke, Canada, 1992 (in French).

[8] B. Miao, P.C. Aïtcin, W.D. CooK, D. Mitchell, Influence of concrete strength on in situ properties of large columns, ACI Mater. J. 90 (3) (1993) 214-219. 